\title{
Social Presence, Network Effect, Cross-Channel Free Riding
}

\author{
Yi Zhang1, Yanan Wang1, Wenxi Guo², Haiquan Chen $^{2 *}$ \\ ${ }^{1}$ Guangdong University of Finance, Guangzhou, China \\ ${ }^{2}$ Jinan University, Guangzhou, China \\ Email: zhangyisg@126.com,592494278@qq.com,breey3041140@126.com,*jnuchen@qq.com
}

How to cite this paper: Zhang, Y., Wang, Y. N., Guo, W. X., \& Chen, H. Q. (2020). Social Presence, Network Effect, CrossChannel Free Riding. American Journal of Industrial and Business Management, 10, 1454-1472.

https://doi.org/10.4236/ajibm.2020.108095

Received: July 30, 2020

Accepted: August 23, 2020

Published: August 26, 2020

Copyright $\odot 2020$ by author(s) and Scientific Research Publishing Inc. This work is licensed under the Creative Commons Attribution International License (CC BY 4.0).

http://creativecommons.org/licenses/by/4.0/

(c) (i) Open Access

\begin{abstract}
This paper aims to analyze the impact mechanism of consumers' social presence on network effect and cross-channel hitchhiking on online shopping platform. In this study, 424 consumers of online shopping platforms were surveyed by questionnaire, and the collected data were analyzed by reliability and validity, exploratory factor analysis, confirmatory factor analysis, and hierarchical regression analysis to examine the research hypothesis. The result showed that: first, the stronger consumers' sense of social presence on the online shopping platform, the more likely they will be able to cross-channel free-riding transferring from one retailer's offline channel to online channel; Second, the stronger consumers' sense of social presence, the more likely they will be able to increase the number of consumers and businesses, and got the same-side network effect and cross-side network effect; Third, the exertion of same-side network effect and cross-side effect on the online shopping platform were beneficial for improving the probability of cross-channel free ride for consumers; Fourth, the same-side network effect and cross-border network effect played a mediating role in social presence and cross-channel free riding. This research further enriched the theoretical research on consumer channel choice and mechanism of action of online retail platforms from the perspective of platform network effect.
\end{abstract}

\section{Keywords}

Online Shopping Platform, Network Effect, Opportunism, Social Presence, Cross-Channel Free-Riding, Platform Users

\section{Introduction}

E-commerce platform is an important virtual place for sellers and buyers (McIntyre \& Srinivasan, 2017), and it was also an intermediary place based on infor- 
mation digital technology to provide online business services for the two sides users (Boudreau \& Jeppesen, 2015). Besides, it provided infinite virtual services for online transactions, and ensured the online transactions to be completed smoothly within a network environment (Hagiu \& Wright, 2015). E-commerce platforms also coordinated and integrated information flow, logistics, capital flow and business flow (Gawer, 2014). Sellers and buyers (including enterprises and individuals) can make full use of shared resources provided by e-commerce platforms such as network infrastructure, payment platform, security platform, management platform to carry out their business activities effectively and cheaply (Zhu \& Iansiti, 2012).

There were still some problems that can't be ignored when business platforms developing rapidly (Eisenmann, Parker, \& Van Alstyne, 2011; Gawer, 2014; McIntyre \& Srinivasan, 2017). Sellers on the platform usually have more information than buyers on the quality, purchase price and color of products in the process of e-commerce platform trading (Wathne \& Heide, 2000). Buyers are often in a weak position in platform trading, which easily leads to some sellers' opportunistic behaviors due to the asymmetry of information between buyers and sellers (Doney \& Cannon, 1997). The information within the platform is not transparent and asymmetric, which is a global issue. Consumers though cannot fully understand the relevant information of the goods before trading, meanwhile, sellers cannot fully grasp the relevant transaction information such as product quality and delivery time. Therefore, there are also some opportunistic behaviors from platform buyers (Huang et al., 2017).

Research about how to reduce opportunistic behaviors of the other two parties at the same time is still not sufficient. Previous studies focused on the governance of opportunistic sellers under the dualistic relationship. The opportunistic behavior of the online buyer is more difficult to govern because their behavior was more concealed than the buyer's improper behavior in the traditional transaction, included other reasons, such as the anonymity of the network, inconsistency of transaction distance and time on the platform, and the no-threshold anonymity of the buyer registration. The ternary relationship composed of platform, seller and buyer were more complex than that of dualistic relationship with the development of e-commerce platform (Armstrong, 2006; Gawer, 2014). besides, stable and orderly online shopping environment requires the concerted efforts of the platform, seller and buyer (Zhu \& Iansiti, 2012).

Buyers cross-channel free-riding generally exists in the medical industry, real estate intermediaries, home shopping malls, electronic products, books, clothing, and other retail industries. In the field of shopping malls leasing, tenants directly trade with customers skipping the platform, though they used the information and services provided by the mall platform. There was once a widespread skipping order phenomenon that patients in the hospital treatment and examination, but in other channels (such as pharmacies outside the hospital, overseas pharmaceutical factories, etc.) at low prices. The Chinese film dying to survive is 
a typical case of skipping orders pharmaceutical products have the same efficacy, but the channel price difference is 120 times. In recent years, this phenomenon had become more and more common. Internet merchants were favored by consumers because of their price advantages, coupled with the improvement of free engine search, logistics market, and other supporting implementations, which have witnessed rapid growth in the last decade. The conflict between offline stores and online merchants is aggravated because of the high channel price difference. It shows two phenomena, on the one hand, customers buy goods directly through online shop rather than physical stores, which is what we called "directly online shopping"; on the other hand, customers try out and experience in the physical store but decide to purchase goods online, which is called "select offline buy online".

Although "Shop Selection Online Purchase" may temporarily bring shoppers greater price differential benefits, it will also greatly affect the enthusiasm of shoppers to promote sales, which seems unsustainable in the long run. Those opportunistic behaviors have seriously affected the normal trading and sustainable development of business platforms and offline markets (Wathne \& Heide, 2000).

In summary, the governance of consumers in the online retail platform should be concerned. How to effectively govern online buyers' opportunism has become the focus and difficulty for the industry and academia (Wathne \& Heide, 2000). On the network retail platform, will consumers' sense of social presence on the network platform lead them to take advantage of cross-channel free rider? If social presence can affect consumers' free rider across the channel, what is the impact on the platform? Does the platform network effect affect consumers' free rider? What is the result? So we study the influence of social presence on crosschannel free-riding of consumers from the perspective of network effect.

The organization of this paper is as follows. Firstly, it combs the research literature of free-rider, social presence and platform network effect, finding the theoretical basis and literature gap of this study; Secondly, it construct a model according to theoretical logic, collects the evaluation of online platform consumers' shopping experience through questionnaire survey method; Finally, it analyses and verifies the collected data using mathematical statistics software to prove the hypothesis which was put forward at the outset, and lastly summarizes the conclusions and theoretical contributions of this study.

\section{Theory and Hypotheses}

\subsection{Social Presence}

With the development and innovation of network technology (Gawer, 2014), as an important concept, social presence has gradually expanded its scope from traditional communication to distance education, human-computer interaction and marketing, describing "the salience of other people's interaction and the consequent salience of their interpersonal interactions". In the field of market- 
ing, related research on social presence appeared relatively lately (Huang et al., 2017). At present, it mainly covered the topics of online service improvement, online shopping, virtual shopping center design (Shin \& Shin, 2011) and network community construction.

Scholars define social presence in marketing field and conduct consumer attitudes and behavioral research around the concept of social presence. For example, Shin \& Shin (2011) defined social presence as a substitute for face-to-face communication (Shin \& Shin, 2011). It is found that social presence can improve consumers' safety perception and purchase attitude in virtual shopping centers, which is the key behavioral prerequisite for using virtual shopping centers (Shin \& Shin, 2011). This research pointed out that the interactive characteristics of websites can promote the comparison of personal presence. Social presence conveyed by websites can influence behavioral intentions by affecting perceptions of pleasure and usefulness. Some scholars believed that social presence was only the evaluation of other people's psychologically real presence, which together with telepresence, which represents physical authenticity, constitutes "virtual presence" and further affects consumers' trust in websites.

Researchers explored the dimensions of social presence in marketing according to the specific research background. Recent studies have found that social presence in online communities was composed of social presence in websites, social presence in others and social presence in communication. These three social factors significantly affect consumers' trust in businesses, social presence in websites, social presence in others and social presence in communication. The higher the perception, the higher the level of consumer trust in the seller, and thus promoted the purchase (Lu, Fan, \& Zhou, 2016).

Many social presence studies have found that there is a close relationship between social presence and online trust. Some scholars found that social presence can positively promote the formation of consumer e-trust and help generate purchase intention. In this study, social presence mainly refers to the personal, social and personal feelings brought by web pages. Studies also show that the increase in social presence can improve consumer trust in sellers. The social presence here refers to the degree of saliency in the interaction of others and the consequent degree of interpersonal relationship (Lu, Fan, \& Zhou, 2016). Similarly, some scholars found that online interaction with businesses can increase the social presence of consumers, and thus enhance consumers' trust in the integrity and bonafide nature of the B2C shop (Lu, Fan, \& Zhou, 2016). Other studies have found that social presence plays a mediating role in perceiving the degree of personalized recommendation on consumers' beliefs of trust in online stores (Choi, Lee, \& Kim, 2011).

Many studies have proved that the presence of others can lead to evaluation scruples. Evaluation scruples refer to the self-generated anxiety of individuals who wish to receive positive comments from others or at least to avoid negative comments from others. Many studies have shown that evaluation scruples can 
be triggered by different social cues, such as the presence of audiences, and even images of eyes (Huang et al., 2017). In a social environment, human-environment-goal activation influences consumers' buying behavior directly or through social interaction in addition to the role of human-goal activation. In the process of consumption, consumers will feel that they are being evaluated by others because of the mere social presence of others and arouse consumers' awareness of self-image management, which increases with the increase of the number of others and their perception of their behavior.

In summary, social presence is an important concept in the field of traditional communication. With the development of modern communication technology, it has been applied and studied in the field of marketing. Existing studies have revealed some effects of social presence on website trust, purchase attitude and purchase behavior. However, in the context of full-channel marketing, consumers get a lot of other people's presence information in real-time, and the social presence that has been studied does not involve the real-time three-dimensional interaction with other consumers, and there was rare research to explore the impact of social presence on platform consumption behavior and its mechanism.

\subsection{Cross-Channel Free Riding}

E-commerce platform is a trading intermediary platform connecting buyers and sellers (Albrecht, Dean, \& Hansen, 2005). Although buyers and sellers share the same goal-completing the transaction, as different stakeholders, there must be inconsistencies in the goal (Devaraj, Fan, \& Kohli, 2002). The above two kinds of relationship structures will also produce incomplete and opaque information (Albrecht, Dean, \& Hansen, 2005). Therefore, both of them tend to be opportunistic as long as conditions permit (Wathne \& Heide, 2000). Although their opportunistic behavior can bring some short-term benefits to themselves, in the long run, it will damage the long-term interests of the trading relationship on the platform and lead to the short-term cooperation. E-commerce platform expanded consumers' shopping channels and provides consumers with a new shopping choice channel. As it crosses the limitations of space and time in shopping (Hagiu \& Wright, 2015), it has become an important mode of consumer shopping.

The network environment has become a new fertile ground for the derivation of immoral behavior with the rise of e-commerce. Network can generate a variety of misconduct, however, the main focus of current research is the governance of vendors by platforms (Grewal, Chakravarty, \& Saini, 2010). The only literature on restraining customer misconduct is mainly from the corporate perspective and the employee perspective, but both perspectives are strong in the negative response of enterprises. Forced or encouraged employees of their own enterprises to accept customers' improper behavior, these strategies are only effective in the short term, and do not substantially reduce customers' improper behavior, cure symptoms and do not cure the root cause. Opportunism is a se- 
ries of improper or destructive acts in which the parties involved in the transaction use fraudulent means in order to obtain short-term self-interest and ignore long-term trading relations. Rokkan \& Buvik (2003) defined opportunism as economic subjects that obtain personal interests through unreasonable and illegal ways (Rokkan \& Buvik, 2003).

From the above-mentioned definition of opportunism by scholars. The concrete manifestations of opportunism are: deceiving, distorting and misleading information, violating contracts, avoiding or not fully fulfilling commitments or obligations and refusing to adapt to changes in circumstances. The forms of opportunism on the platform involved in this study are: concealing the quality of goods, defrauding compensation, malicious evaluation and so on.

It can be found that both customer self-interest behavior and platform governance lack attention to online customer self-interest behavior and its countermeasures. It is very urgent to study online customer self-interest behavior and how to reduce online customer self-interest behavior. At present, the research on the platform has been very extensive and in-depth, but no scholar has studied the serious problem that the industry is facing-opportunism of the buyer. Although on e-commerce platform, due to information asymmetry, buyers tend to be vulnerable, and customer orientation (customer sovereignty theory) has become the basis of marketing theory, "customers are always right" and "customers are God" have been accepted by most people, but we cannot think that customers' opportunism or misconduct does not exist in e-commerce, but is more hidden and frequent than in traditional transactions. Some bad buyers will use the imbalance of platform supervision to cheat sellers, such as malignant bad reviews to coerce sellers to pay a certain amount of compensation before changing their comments. E-commerce platforms usually formulate detailed management rules for sellers stationed on platforms, and sellers will be punished when they violate the trading system established by platforms (Gawer, 2014). But the platform cannot manage the buyer. Therefore, the study of buyer opportunism should not be neglected when researching the smart platform. This paper is based on exploring the influence of presence on buyer opportunism.

\subsection{Platform Network Effect}

In the relevant literature of the platform, where users (e.g. buyers and sellers) exchange goods, services and information, at least one side of has "cross-group network externalities" (also called network effects) can be considered as a two-side market (Afuah, 2013; Chintakananda \& McIntyre, 2014; Shankar \& Bayus, 2003). Shared accommodation platform (i.e. Airbnb) is a typical two-side market, which connects two specific groups of landlords and tenants. Through relevant mechanisms, it constantly stimulates positive network effects (Chintakananda \& McIntyre, 2014), and achieves stable and long-term development of the platform on the premise of meeting the needs of both landlords and tenants (Ansari, Garud, \& Kumaraswamy, 2016). Network effect is one of the key factors for plat- 
form development and growth, including the same-side network effect and crossside network effect (Boudreau \& Jeppesen, 2015; Parker \& Van Alstyne, 2005; Shankar \& Bayus, 2003). The same-side network effect means that the increase of the number of users on one side of the platform will affect the utility of users on the other side (Church \& Gandal, 1992). The cross-border network effect is that the increase of the number of users on one side of the platform will affect the utility of users on the other side (Church \& Gandal, 1992). The existence of network effects has an important impact on the behavior of platform participants (Zhu \& Iansiti, 2012). Platform enterprises hope to stimulate positive network effects (i.e., the number and utility are positively correlated) (Dubois \& Gadde, 2000; Eisenmann, Parker, \& Van Alstyne, 2011; Gawer, 2014; Katona, Zubcsek, \& Sarvary, 2011). For example, the subsidy war between Didi and Meituan hopes to reach the trigger point of network effects and ensure the development of the platform.

As for the research of platform network effect, the current literature mainly focuses on the traditional e-commerce platform and software development platform (Chu \& Manchanda, 2016), explores the impacts of the same-side network effect (direct network effect) and cross-side network effect (indirect network effect or cross-network effect) on platform operation (Afuah, 2013; Church \& Gandal, 1992; Dubois \& Gadde, 2000; Parker \& Van Alstyne, 2005). For example, Chu and Manchanda (2016) has studied the direct network effect and cross-border network effect on the Taobao platform. Empirical results show that for the growth of the platform, the direct network effect plays a relatively small role, and found that both sides of the Taobao platform have a large positive cross-border network effect (Chu \& Manchanda, 2016). Some scholars also studied the mechanism of cross-border network effects caused by two kinds of platform governance (platform update and APP audit time) (Boudreau \& Jeppesen, 2015).

In summary, the platform network effect has important practical significance for the bilateral development of the platform. However, the literature of the network trading platform lacks the discussion of the platform network effect, especially the research of the network effect on the buyer's multi-channel free rider.

\subsection{Hypotheses}

In this study, cross-channel free-rider refers to the process of consumers' transfer from offline channels to online channels. This process includes not only the process of consumers' transfer from one retail entity store channel to another online store channel but also the transfer between information search channel and purchase channel. As a kind of perception, the sense of presence emphasizes the sense of the real degree of the individual as the subject in the virtual environment (Lu, Fan, \& Zhou, 2016). On the network platform, the interaction between consumers and online sellers and the interaction between consumers are 
social, especially good interaction is bidirectional and cordial, so it can create a warm sense of social presence (Choi, Lee, \& Kim, 2011). The high-quality interaction between consumers and online sellers can make consumers feel that they are bargaining at entity stores, and even feeling that everything is just around the corner (Shin \& Shin, 2011). Interaction among consumers is often the experience of online shopping and the evaluation of goods and services, which is mutually beneficial and nonutilitarian, could easily to arouse the resonance between consumers, and the interaction between consumers (Choi, Lee, \& Kim, 2011). More relaxed, less alert. According to the theory of social promotion, awareness of other people's presence can lead to individual alertness, thus triggering the awakening of individual psychology. Stimulus-mechanism-response theory holds that the environment can arouse individual psychological pleasure, and then affect individual behavior. The sense of presence can enhance the authenticity of online shopping (Shin \& Shin, 2011), arouse consumers' trust in online shopping, and then promote consumers' willingness to the cross-channel free rider (Rokkan \& Buvik, 2003). Based on this, this study proposes the following hypothesis:

H1: Social presence has a positive impact on cross-channel free rider. The stronger the social presence of consumers on the online shopping platform, the higher the probability of cross-channel free rider.

The sense of social presence closes the physical and psychological distance between not only consumers, but also between consumers and sellers on the network platform, which makes consumers feel the real existence of online stores and products, and generate a sense that everything is in front of them, which makes consumers experience that online stores have the scale and strength to provide good products and services (Lu, Fan, \& Zhou, 2016). To some degree customers' presence can increase their interaction and trust with other consumers, and then through the interaction to obtain the information needed for goods and services, reduce the risk of shopping (Lu, Fan, \& Zhou, 2016). Therefore, the presence of consumers will increase the trust between consumers (Shin \& Shin, 2011), and then attract more consumers to buy on the platform, which is conducive to the exertion of the network effect on the same side of the platform (Afuah, 2013). Consumers' perception of the trustworthiness and goodwill of online stores is mainly based on the judgment of subjective factors such as long-term consideration (Katona, Zubcsek, \& Sarvary, 2011), honesty and trustworthiness such as the belief that online stores will fulfill the agreements reached with consumers, and will not cause customer loss due to short-term interests, and legal operation of online stores, etc. consumers' social presence describes that they are together with online sellers and other consumers (Katona, Zubcsek, \& Sarvary, 2011). The feeling of getting along with each other, generally speaking, is that people around us, whether working or trading, are more likely to believe that these people are honest and good-faith when the relationship is warm and harmonious. Therefore, consumers' sense of social pres- 
ence will increase consumers' trust in sellers, and then choose the network platform for shopping, which is conducive to the platform activating the cross-sided network effect. Therefore, this study proposes the following hypothesis:

H2a: Social presence positively affects the same-side network effect. The stronger the social presence of consumers on the online shopping platform, the more they can promote the increase of the number of users on the same side and bring into play the network effect on the same side.

$\mathrm{H} 2 \mathrm{~b}$ : Social presence positively affects cross-sided network effects. The stronger the social presence of consumers on the online shopping platform, the more they can promote the number of users at the other end of the network to increase and play a cross-sided network effect.

Platform of online shopping plays an important role in enhancing the attractiveness of consumers. On the one hand, the stimulation of the same-side effect on the online shopping platform can promote the communication and interaction between consumers (Katona, Zubcsek, \& Sarvary, 2011), enhance the environment atmosphere of consumers' safe transactions (Huang et al., 2017), and make consumers feel the strong user base of the online platform (Shankar \& Bayus, 2003). The interaction between consumers is to get suggestions from other consumers' evaluation and share shopping feelings with other consumers (Lu, Fan, \& Zhou, 2016). Therefore, consumers can interact with each other. Interaction can greatly reduce consumers' perceived risk (Shin \& Shin, 2011), make consumers believe that the platform can provide the products and services they need, protect consumers' demands, and ensure transaction security, so that customers will ultimately choose to shop on the network platform which naturally leads to cross-channel free rider. On the other hand, the stimulation of the cross-sided effect of the network is conducive to the formation of positive feedback mechanism between the demand side and the supply side (Huang et al., 2017), which enables consumers to feel the strong strength of the network platform when choosing shopping channels (Lu, Fan, \& Zhou, 2016), promotes the interaction between consumers and sellers on the platform (Parker \& Van Alstyne, 2005), enables consumers to fully understand the information about product quality, price and service (Choi, Lee, \& Kim, 2011), which reduces the impact on sellers in the process of online shopping. Perception of risk, and allow consumers to experience the convenience of online shopping in interaction, and then guide consumers to shop on the network platform, leading to cross-channel free-rider behavior. Therefore, this study proposes the following hypothesis:

H3a: The same-side network effect has a positive impact on cross-channel free rider. Playing the same side network on the online shopping platform is conducive to improving the probability of cross-channel convenience for consumers.

H3b: Cross-sided network effect has a positive impact on cross-channel free rider. The development of cross-sided network on online shopping platform is conducive to raise the probability of cross-channel convenience for consumers.

Consumers' social presence on the online shopping platform is conducive to 
promote users to take advantage of the platform network effect, and the activation of the platform network effect is conducive to guiding consumers to shop on the network platform and triggering cross-channel free-riding behavior. On the one hand, when the number of users on one side of the platform increases, it will affect the users' efficiency on the same side (Shankar \& Bayus, 2003). The interaction between consumers and online sellers or consumers is interpersonal, social, bidirectional and cordial, which creates a warm social presence. Interaction between consumers could often promote communication and render customers generate resonance, which may help attract more experienced consumers to enter the platform and activate the network effects on the same side of the platform (Boudreau \& Jeppesen, 2015). The stronger the same-side network effect of the online shopping platform means that more consumers are shopping on the platform. The more welfare the consumers get, the more types, cheaper products, and better-quality products will be available (Adner \& Kapoor, 2010). The after-sale service on the platform will also be more secure, and shopping will be more convenient and faster, so it will be more conducive to attracting more consumers. Consumers shop on the Internet platform, leading to cross-channel free-rider behavior. On the other hand, the increase of user scale on one side of the platform will affect the other users' efficiency on the other side. The online shopping platform and the reasonable design of the store to the seller can facilitate the smooth communication between consumers, consumers, and sellers, and give consumers a strong sense of social presence (Dubois \& Gadde, 2000; Huang et al., 2017), meanwhile pull the psychological distance between consumers and sellers, and let consumers experience the goods and services with high quality and low price on the online shopping platform, thus attracting more consumers to enter the shopping platform ( $\mathrm{Lu}, \mathrm{Fan}, \&$ Zhou, 2016). As a result, more platform sellers will be attracted to the shopping platform. Once breaking through the critical point, it will stimulate cross-sided network effect (Chu \& Manchanda, 2016), and activate the positive feedback mechanism between the supply side and the demand side, so as to form a closer dependence relationship between the two sides, thus triggering consumers to take cross-channel free rider that purchase goods online shops rather than physical stores. Therefore, this study proposes the following hypothesis:

H4a: Same-sides network effect mediate social presence and cross-channel free rider.

H4b: Cross-sides network effect mediates social presence and cross-channel free rider.

This paper will find out the mature questionnaire and make appropriate modification according to the actual situation, then issue the survey questionnaire through various channels, and check the returned questionnaire one by one, eliminated low reliability questionnaire, and then use SPSS 22.0 and Amos for statistical analysis of the collected samples, the main statistical methods include reliability and validity analysis, descriptive statistics, regression analysis. 


\section{Data and Methods}

The initial questionnaire from the scale tools used by scholars was revised according to online retail platform. The questionnaire was adjusted according to the pre-survey results which were a total of 26 online retail platform consumers. This questionnaire mainly included two parts: the first part was the main part of the scale, including four variables of the research model, each variable was measured by $3 \sim 5$ indicators, and measured by Likert scale 5, 1 means "very inconsistent", 2 means "more inconsistent", 3 means "commonly", 4 means "more consistent", 5 means "very consistent"; the second part was the basic information of online retail platform consumers, including gender, age, education background, occupation, and monthly income.

\subsection{Dependent Variable}

\section{Cross-channel free riding}

This study defined the concept of channel hitchhiking, and defined the cross-channel free-riding behavior as the process of consumers transferring from one retailer's offline channel to another online channel (Chiu et al., 2011; Heitz-Spahn, 2013). According to the research of Van Baal \& Dach (2005), there were 3 items to measure cross-channel free riding, including: 1) Did you gather information in an online shop before the purchase in the store? 2) Did you gather information in a store before the purchase in the online shop? 3) Did you gather information in the store of the retailer and then chose to buy it in an online shop?

\subsection{Independent Variables}

\subsubsection{Social Presence}

Based on the research of Hassanein \& Head (2007), there were 4 items to measure cross-sides network effect, including: 1) there is a sense of human contact on this online shop; 2) there is a sense of intimacy on this online shop; 3 ) there is a sense of sociability on this online shop; 4) there is a sense of human warmth on this online shop.

\subsubsection{Network Effect}

Based on the research of McIntyre \& Srinivasan (2017), Parker \& Van Alstyne (2005), a total of 10 items were designed, including two concepts: the same-sides network effect and the cross-sides network effect. There were 5 items to measure cross-sides network effect, including: 1) this online retail platform has a large number of business users; 2) the merchants of this online retail platform are friendly and easy to communicate; 3 ) the merchants of this online retail platform can meet my needs; 4) the retailers of this online retail platform have good returns; 5) more and more businesses will use this online retail platform. We also use 5 items to measure same-sides network effect, including: 1) this online retail platform has more active consumers; 2) More orders from consumers on this online retail platform; 3) The consumer quality of this online retail platform is 
high; 4) The consumer viscosities of this online retail platform are high; 5) this online retail platform will have more consumers in the future.

\subsection{Control Variables}

This paper also takes the gender, age, education background, occupation and monthly income of the online retail platform as the control variables. Gender was a dummy variable; Age, education background, occupation, and monthly income were classified variables.

\subsection{Statistical Method and Analysis}

This study mainly collected first-hand data by questionnaire survey, which includes two stages: pre-survey and formal survey. The pre-survey time was September 24, 2019. The survey respondents were consumers in the comprehensive retail platform such as Taobao, JD.com, Tmall, Gome, Amazon, and Dangdang. A total of 26 questionnaires were eventually collected. According to the preliminary analysis of the questionnaire data, including exploratory factor analysis and confirmatory factor analysis, combined with the opinions of some experts, some items were revised and deleted, and finally, the formal research scale was obtained. In the formal survey stage, 424 questionnaires were valid from 24 September to 26 September 2019 on Wechat, and the effective recovery rate of the questionnaires was $96 \%$. The demographic information of the online retail platform investigated by this research was as follows in Table 1. Females tend to have more gender orientation; young and middle-aged is mainly sample; education experience was mainly college or undergraduate; occupation was mainly students, and monthly income was mostly less than $1000 \mathrm{RMB}$.

\section{Results}

The reliability and validity of the questionnaire were analyzed by SPSS 22.0 and AMOS 18.0. Firstly, exploratory factor analysis (EFA) was carried out by SPSS 22.0. Questions with factor load less than 0.5 were deleted (Table 3), and the KMO statistic was 0.804 , which was tested at a significant level of 0.000 (Table 2). This exploratory factor analysis extracts five factors: social presence (SP), network effect on the same side (SNE), cross-border network effect (CNE) and cross-channel free rider (CFR), and explains $63.38 \%$ of the variance, so the scale had good validity. Besides, the reliability of the scale was guaranteed by the fact that all the concepts of Cronbach alpha and C.R. are above 0.7.

AMOS 18.0 was used to conduct confirmatory factor analysis (CFA). The results showed that the model had good fitness, the factor load was above 0.50 , and the average extraction variance (AVE) of all constructions was above 0.45 , which indicated that the constructions in this study had good polymerization validity. We calculated the factor score of each concept, then take the concept score as the basis of data analysis in the next step. The descriptive statistical information and correlation matrix of the constructions were shown in Table 3 and Table 4. 
Table 1. Sample $(N=424)$.

\begin{tabular}{|c|c|c|c|c|c|c|c|}
\hline & Categories & Sample & Proportion/\% & & Categories & Sample & Proportion/\% \\
\hline \multirow{2}{*}{$\operatorname{sex}$} & male & 124 & 29.20 & \multirow{6}{*}{ age } & $<16$ & 5 & 1.20 \\
\hline & female & 300 & 70.80 & & $16 \sim 25$ & 319 & 75.20 \\
\hline \multirow{4}{*}{ education } & young school & 8 & 1.90 & & $26 \sim 35$ & 90 & 21.20 \\
\hline & high school & 14 & 3.30 & & $36 \sim 45$ & 7 & 1.70 \\
\hline & colle./undergra. & 268 & 63.20 & & $46 \sim 55$ & 1 & 0.20 \\
\hline & graduate & 134 & 31.60 & & $>55$ & 2 & 0.50 \\
\hline \multirow{8}{*}{ occupation } & student & 265 & 62.50 & \multirow{8}{*}{$\begin{array}{l}\text { income } \\
\text { (RMB) }\end{array}$} & $<1000$ & 143 & 33.70 \\
\hline & teacher & 21 & 5.00 & & $1001-2000$ & 103 & 24.30 \\
\hline & clerk & 84 & 19.80 & & $2001-3000$ & 38 & 9.00 \\
\hline & civil servants & 18 & 4.20 & & $3001-4000$ & 29 & 6.80 \\
\hline & self-employed & 4 & 0.90 & & $4001-5000$ & 19 & 4.50 \\
\hline & liberal & 17 & 4.00 & & $5001-7000$ & 39 & 9.20 \\
\hline & unemployed & 9 & 2.10 & & $7001-10,000$ & 23 & 5.40 \\
\hline & other & 6 & 1.40 & & $>10,000$ & 30 & 7.10 \\
\hline
\end{tabular}

Table 2. KMO and Bartlett's test.

\begin{tabular}{|c|c|c|}
\hline \multicolumn{2}{|c|}{ Kaiser-Meyer-Olkin Measure of Sampling Adequacy. } & 0.804 \\
\hline Bartlett's Test of Sphericity & Approx. Chi-Square & 2843.414 \\
\hline & df & 351 \\
\hline & Sig. & 0.000 \\
\hline
\end{tabular}

Table 3. Reliability and validity analysis.

\begin{tabular}{|c|c|c|c|c|c|}
\hline Construction & Items & Loading & Cronbach $\alpha$ & C.R. & AVE \\
\hline \multirow{4}{*}{$\begin{array}{l}\text { perceived social } \\
\text { presence }\end{array}$} & There is a sense of human contact on this online shop & $0.667^{* * *}$ & \multirow{4}{*}{0.792} & \multirow{4}{*}{0.795} & \multirow{4}{*}{0.495} \\
\hline & There is a sense of intimacy on this online shop & $0.649^{* * *}$ & & & \\
\hline & There is a sense of sociability on this online shop & $0.805^{* * *}$ & & & \\
\hline & There is a sense of human warmth on this online shop & $0.682^{* * *}$ & & & \\
\hline \multirow{3}{*}{$\begin{array}{c}\text { cross-side } \\
\text { network effect }\end{array}$} & This online retail platform has a large number of business users & $0.689^{* * *}$ & \multirow{3}{*}{0.734} & \multirow{3}{*}{0.749} & \multirow{3}{*}{0.504} \\
\hline & The merchants of this online retail platform are friendly and easy to communicate & $0.827^{* * *}$ & & & \\
\hline & The merchants of this online retail platform can meet my needs & $0.594^{* * *}$ & & & \\
\hline \multirow{3}{*}{$\begin{array}{c}\text { same-side } \\
\text { network effect }\end{array}$} & This online retail platform has more active consumers & $0.666^{* * *}$ & \multirow{3}{*}{0.823} & \multirow{3}{*}{0.828} & \multirow{3}{*}{0.619} \\
\hline & More orders from consumers on this this online retail platform & $0.806^{* * *}$ & & & \\
\hline & This online retail platform will have more consumers in the future & $0.874^{* * *}$ & & & \\
\hline \multirow{2}{*}{$\begin{array}{l}\text { cross-channel } \\
\text { free riding }\end{array}$} & Did you gather information in a store before the purchase in the online shop? & $0.823^{* * *}$ & \multirow[b]{2}{*}{0.740} & \multirow[b]{2}{*}{0.751} & \multirow[b]{2}{*}{0.528} \\
\hline & $\begin{array}{l}\text { Did you gather information in the store of the retailer and then chose } \\
\text { to buy in online shop? }\end{array}$ & $0.700^{* * *}$ & & & \\
\hline
\end{tabular}


Table 4. Descriptive statistical and correlation matrix.

\begin{tabular}{|c|c|c|c|c|c|c|c|c|c|}
\hline & 1 & 2 & 3 & 4 & 5 & 6 & 7 & 8 & 9 \\
\hline sex & 1 & & & & & & & & \\
\hline age & -0.044 & 1 & & & & & & & \\
\hline edu & 0.029 & $0.242^{* *}$ & 1 & & & & & & \\
\hline occu & 0.004 & $0.336^{* *}$ & $-0.120^{*}$ & 1 & & & & & \\
\hline income & -0.027 & $0.472^{* *}$ & $0.190^{* *}$ & $0.504^{* *}$ & 1 & & & & \\
\hline SP & -0.011 & -0.045 & 0.014 & -0.008 & -0.013 & 1 & & & \\
\hline SNE & $0.171^{* *}$ & $-0.154^{* *}$ & $0.100^{*}$ & $-0.153^{\star *}$ & -0.071 & $0.321^{* *}$ & 1 & & \\
\hline CNE & $0.241^{* *}$ & -0.075 & 0.062 & -0.053 & -0.011 & $0.232^{* *}$ & $0.689^{* *}$ & 1 & \\
\hline CFR & $0.141^{* *}$ & -0.008 & 0.007 & -0.026 & -0.061 & $0.131^{* *}$ & $0.177^{* *}$ & $0.262^{\star *}$ & 1 \\
\hline Mean & 1.710 & 2.260 & 3.250 & 2.040 & 3.090 & 3.223 & 3.779 & 3.757 & 2.889 \\
\hline Std. De. & 0.455 & 0.566 & 0.604 & 1.663 & 2.304 & 0.6925 & 0.5922 & 0.6576 & 0.8222 \\
\hline
\end{tabular}

${ }^{*}$ 1. sex, 2.age, 3. education, 4. occupation, 5.income, 6. perceived social presence, 7. same-side network effect, 8 . cross-side network effect, 9.cross-channel free riding.

As shown in Table 5 social presence has a positive impact on cross-channel free rider $(\mathrm{M} 1, \mathrm{M} 2$, beta $=0.210, P<0.01$ ), hypothesis $\mathrm{H} 1$ is verified; the same-side network effect has a positive impact on cross-channel free rider (M1, $\mathrm{M} 3$, beta $=0.177, P<0.01$ ), hypothesis $\mathrm{H} 3 \mathrm{a}$ is validated; and the cross-side network effect has a positive impact on cross-channel free rider (M1, M3, beta = $0.177, P<0.01$ ). Influences (M1, M4, beta $=0.343, P<0.001$ ), hypothesis H3b is verified; then using same-side network effect and cross-border network as dependent variables respectively to do regression analysis, results shows that social presence positively affects the same-side network effect (M5, M6, beta $=0.192, P$ $<0.001$ ), hypothesis $\mathrm{H} 2 \mathrm{a}$ is validated; social presence positively affects the cross-border network effect (M7, M8, beta $=0.185, P<0.001)$, hypothesis H2b is verified.

As shown in Table 6, the same-side network effect partially mediates between social presence and cross-channel free rider (M1, M2, M3, beta $=0.138, P<$ 0.05), hypothesis $\mathrm{H} 4 \mathrm{a}$ is verified; the cross-side network effect partially mediates between social presence and cross-channel free rider (M4, M5, M6, beta $=0.315$, $P<0.001$ ), hypothesis $\mathrm{H} 4 \mathrm{~b}$ is verified.

\section{Discussion and Conclusions}

The purpose of this study is to explore the influence mechanism of consumers' social presence on cross-channel free rider from the perspective of platform network effect. Based on the relevant literature of network platforms and the perspective of the platform network effect, this study conducts empirical research based on 424 consumers' survey data about the online retail platform. The conclusions are as follows: social presence, the same-side network effect and the cross-border network effect have significant positive effects on cross-channel 
Table 5. Hierarchical regression analysis.

\begin{tabular}{ccccccccc}
\hline & \multicolumn{3}{c}{$\mathrm{FR}$} & \multicolumn{5}{c}{$\mathrm{SNE}$} \\
\cline { 2 - 8 } & $\mathrm{M} 1$ & $\mathrm{M} 2$ & $\mathrm{M} 3$ & $\mathrm{M} 4$ & $\mathrm{M} 5$ & $\mathrm{M} 6$ & $\mathrm{M} 7$ & $\mathrm{M} 8$ \\
\hline sex & $0.315^{* *}$ & $0.323^{* *}$ & $0.258^{* *}$ & $0.197^{*}$ & $0.321^{* * *}$ & $0.328^{* * *}$ & $0.344^{* * *}$ & $0.351^{* * *}$ \\
age & 0.059 & 0.076 & 0.089 & 0.093 & $-0.172^{*}$ & $-0.156^{*}$ & -0.100 & -0.085 \\
edu & 0.079 & 0.075 & 0.057 & 0.039 & $0.124^{*}$ & $0.121^{*}$ & 0.115 & 0.112 \\
occu & 0.004 & 0.002 & 0.013 & 0.002 & $-0.052^{*}$ & $-0.053^{*}$ & 0.006 & 0.005 \\
income & -0.027 & -0.027 & -0.031 & -0.029 & 0.020 & 0.020 & 0.005 & 0.005 \\
SP & & $0.210^{* *}$ & & & & $0.192^{* * *}$ & & $0.185^{* * *}$ \\
SNE & & & $0.177^{* *}$ & & & & & \\
CNE & & & & $0.343^{* * *}$ & & & & \\
$\mathrm{R}^{2}$ & 0.031 & 0.059 & 0.049 & 0.104 & 0.088 & 0.126 & 0.059 & 0.092 \\
$\Delta \mathrm{R}^{2}$ & 0.031 & 0.028 & 0.018 & 0.072 & 0.088 & 0.038 & 0.059 & 0.033 \\
$\mathrm{~F}$ & $2.715^{*}$ & $4.359^{* * *}$ & $3.583^{* *}$ & $8.063^{* * *}$ & $8.116^{* * *}$ & $10.023^{* * *}$ & $5.242^{* * *}$ & $7.015^{* * *}$ \\
\hline
\end{tabular}

${ }^{* * *}<0.001,{ }^{* *} p<0.01,{ }^{*} p<0.05$. The coefficients in the table are non-standardized coefficients.

Table 6. Hierarchical regression analysis.

\begin{tabular}{ccccccc}
\hline & M1 & M2 & M3 & M4 & M5 & M6 \\
\hline sex & $0.315^{* *}$ & $0.323^{* *}$ & $0.278^{* *}$ & $0.315^{* *}$ & $0.323^{* *}$ & $0.212^{*}$ \\
age & 0.059 & 0.076 & 0.098 & 0.059 & 0.076 & 0.103 \\
edu & 0.079 & 0.075 & 0.059 & 0.079 & 0.075 & 0.040 \\
occu & 0.004 & 0.002 & 0.010 & 0.004 & 0.002 & 0.001 \\
income & -0.027 & -0.027 & -0.030 & -0.027 & -0.027 & -0.029 \\
SP & & $0.210^{* *}$ & $0.183^{* *}$ & & $0.210^{* *}$ & $0.152^{*}$ \\
SNE & & & $0.138^{*}$ & & & \\
CNE & & & & & & $0.315^{* * *}$ \\
$\mathrm{R}^{2}$ & 0.031 & 0.059 & 0.069 & 0.031 & 0.059 & 0.118 \\
$\Delta \mathrm{R}^{2}$ & 0.031 & 0.028 & 0.010 & 0.031 & 0.028 & 0.059 \\
$\mathrm{~F}$ & $2.715^{*}$ & $4.359^{* * *}$ & $4.418^{* * *}$ & $2.715^{*}$ & $12.211^{\star * *}$ & $27.746^{* * *}$ \\
\hline
\end{tabular}

${ }^{* * *}<0.001,{ }^{* *} p<0.01,{ }^{*} p<0.05$. The coefficients in the table are non-standardized coefficients.

free rider; the same-side network effect and the cross-border network effect play a partly intermediary role between social presence and cross-channel free rider. This paper draws three conclusions and theoretical contributions.

Firstly, social presence and network effects have a significant positive impact on cross-channel free rider. The conclusions of this study further enrich the theoretical research of the Internet platform. At present, the research on the opportunism of platform users is relatively rare in an academic circle (McIntyre \& Srinivasan, 2017). Scholars focus more on the opportunism of platform sellers (Heitz-Spahn, 2013). While social presence is an important factor affecting con- 
sumers' choice of shopping channels, scholars have not yet explained clearly how social presence affects consumers on the online retail platform. Besides, the impact of network effects on channel choice of platform consumers is rare in the existing research (Boudreau \& Jeppesen, 2015). Therefore, this study analyses the impact of social presence and network effect on cross-channel free-rider, further enriches the platform theory, enriches the consumer channel selection and mechanism research of online retail platforms.

Secondly, social presence has a significant positive impact on the same-side network effect and cross-border network effect. This study further enriches and improves the theoretical research on the network effects of platform enterprises. The platform network effect is one of the most important characteristics that platform enterprises are different from traditional enterprises (McIntyre \& Srinivasan, 2017), and it is also an important reason that platform enterprises attract platform users to enter the platform and attract them to purchase on the platform. At present, the academic research on the network effect of the platform mainly focuses on the positive feedback mechanism and conditions needed to stimulate the network effect of the platform. Yet, the influence of social presence on the network effect of the platform is seldom studied (McIntyre \& Srinivasan, 2017). Therefore, this study concludes that social presence has a positive impact on the platform network effect, which further enriches the theoretical research on the platform network effect and the theoretical research on the antecedents of the platform network effect (Parker \& Van Alstyne, 2005).

Thirdly, the network effect plays partly an intermediary role between social presence and cross-channel free rider. This shows that in the process of social presence on cross-channel free rider, when consumers perceive the increasing number and quality of users on the platform, they can get more benefits from platform consumption, and then more cross-channel free-rider exists. Some scholars have pointed out that the existence of network effect can promote the exponential growth of platform users (McIntyre \& Srinivasan, 2017), and this positive feedback mechanism helps to explain the mechanism of social presence on cross-channel free rider (Chiu et al., 2011). Therefore, the theoretical contribution of this study is to find that both the same-side network effect and cross-border network effect play a partly intermediary role between social presence and cross-channel free rider, thus may further enrich the theoretical study of the network effect.

\subsection{Implications}

The main conclusions of this paper provide a certain basis for promoting the long-term stable development of the online retail platform, and have important practical enlightenment on how to exert the network effect to achieve sustainable development of the platform, mainly reflected in the following two aspects:

First of all, we should pay attention to the influence of on-the-spot feeling on consumers' purchase decisions through physical examination. The online retail 
platform can improve social presence through a series of measures, which could enhance the personality and vividness of the website and could help to design exquisite pages and personalized website style; The online retail platform can provide detailed product descriptions, emotional copywriting, lifelike 3D technology to create a relaxed online community atmosphere; it can also strengthen the human-computer interaction between online shopping platform and consumers, through timely feedback, encouraging consumer participation. And, provide a platform for human-computer communication especially communication between customers, which improves customers' on-the-spot feelings.

Secondly, we should attach importance to the role of the network effect on the platform. The same-side network effect and cross-border network effect are very important to the development of platform enterprises. The same-side network effect is beneficial to the increase in the number of users and the improvement of welfare on the same side of the platform. The cross-border network effect is the key and core to stimulate the rapid growth of both supply and demand sides as well as the growth of the platform. Therefore, it is necessary to strengthen the governance of bilateral users of the platform, standardize the of users' behaviors within the platform, reduce the possibility of misconduct, safeguard the legitimate interests of bilateral users of the platform, form a positive feedback mechanism of network effect, and realize the sustainable development of the platform.

\subsection{Limitations and Future Research}

Some limitations of this study may suggest directions for future research. Firstly, the regulation of network effect. Some scholars have noticed that the network effect has a moderating effect on the users' behaviors on the platform, and the decision-making behavior pattern will change in different situations of the network effect. Therefore, in the future, we can also analyze the consumer's crosschannel free-rider behavior or sellers' opportunistic behavior in network effect situations on different levels. For example, what are the characteristics of consumer's cross channel free rider behavior under high and low network effects? Then, the cross-border network effect also involves both supply-side and demand-side use. It is difficult to acquire data of users on both sides of supply and demand while pairing users on the same platform at the same time. In the future, it is possible to pair samples between both sides of supply and demand.

\section{Conflicts of Interest}

The authors declare no conflicts of interest regarding the publication of this paper.

\section{References}

Adner, R., \& Kapoor, R. (2010). Value Creation in Innovation Ecosystems, How the Structure of Technological Interdependence Affects Firm Performance in New Technology Generations. Strategic Management Journal, 31, 306-333. 
https://doi.org/10.1002/smj.821

Afuah, A. (2013). Are Network Effects Really All about Size? The Role of Structure and Conduct. Strategic Management Journal, 34, 257-273. https://doi.org/10.1002/smj.2013

Albrecht, C. C., Dean, D. L., \& Hansen, J. V. (2005). Marketplace and Technology Standards for B2B E-Commerce, Progress, Challenges, and the State of the Art. Information \& Management, 42, 865-875. https://doi.org/10.1016/j.im.2004.09.003

Ansari, S. S., Garud, R., \& Kumaraswamy, A. (2016). The Disruptor's Dilemma, TiVo and the U.S. Television Ecosystem. Strategic Management Journal, 37, 1829-1853.

https://doi.org/10.1002/smj.2442

Boudreau, K. J., \& Jeppesen, L. B. (2015). Unpaid Crowd Complementors, the Platform Network Effect Mirage. Strategic Management Journal, 36, 1761-1777. https://doi.org/10.1002/smj.2324

Chintakananda, A., \& McIntyre, D. P. (2014). Market Entry in the Presence of Network Effects. Journal of Management, 40, 1535-1557. https://doi.org/10.1177/0149206311429861

Chiu, H., Hsieh, Y., Roan, J., Tseng, K., \& Hsieh, J. (2011). The Challenge for Multichannel Services, Cross-Channel Free-Riding Behavior. Electronic Commerce Research and Applications, 10, 268-277. https://doi.org/10.1016/j.elerap.2010.07.002

Choi, J., Lee, H. J., \& Kim, Y. C. (2011). The Influence of Social Presence on Customer Intention to Reuse Online Recommender Systems, the Roles of Personalization and Product Type. International Journal of Electronic Commerce, 16, 129-154.

https://doi.org/10.2753/JEC1086-4415160105

Chu, J., \& Manchanda, P. (2016). Quantifying Cross and Direct Network Effects in Online Consumer-to-Consumer Platforms. Marketing Science, 35, 870-893. https://doi.org/10.1287/mksc.2016.0976

Church, J., \& Gandal, N. (1992). Network Effects, Software Provision, and Standardization. The Journal of Industrial Economics, 40, 85-103. https://doi.org/10.2307/2950628

Devaraj, S., Fan, M., \& Kohli, R. (2002). Antecedents of B2C Channel Satisfaction and Preference, Validating E-Commerce Metrics. Information Systems Research, 13, 316-333. https://doi.org/10.1287/isre.13.3.316.77

Doney, P. M., \& Cannon, J. P. (1997). An Examination of the Nature of Trust in Buyer-Seller Relationships. Journal of Marketing, 61, 35-51. https://doi.org/10.1177/002224299706100203

Dubois, A., \& Gadde, L. (2000). Supply Strategy and Network Effects-Purchasing Behaviour in the Construction Industry. European Journal of Purchasing \& Supply Management, 6, 207-215. https://doi.org/10.1016/S0969-7012(00)00016-2

Eisenmann, T., Parker, G., \& Van Alstyne, M. (2011). Platform Envelopment. Strategic Management Journal, 32, 1270-1285. https://doi.org/10.1002/smj.935

Gawer, A. (2014). Bridging Differing Perspectives on Technological Platforms, toward an Integrative Framework. Research Policy, 43, 1239-1249.

https://doi.org/10.1016/j.respol.2014.03.006

Grewal, R., Chakravarty, A., \& Saini, A. (2010). Governance Mechanisms in Business-toBusiness Electronic Markets. Journal of Marketing, 74, 45-62.

https://doi.org/10.1509/jmkg.74.4.045

Hagiu, A., \& Wright, J. (2015). Multi-Sided Platforms. International Journal of Industrial Organization, 43, 162-174. https://doi.org/10.1016/j.ijindorg.2015.03.003

Hassanein, K., \& Head, M. (2007). Manipulating Perceived Social Presence through the Web Interface and Its Impact on Attitude towards Online Shopping. International Jour- 
nal of Human-Computer Studies, 65, 689-708.

https://doi.org/10.1016/j.ijhcs.2006.11.018

Heitz-Spahn, S. (2013). Cross-Channel Free-Riding Consumer Behavior in a Multichannel Environment, an Investigation of Shopping Motives, Sociodemographics and Product Categories. Journal of Retailing and Consumer Services, 20, 570-578. https://doi.org/10.1016/j.jretconser.2013.07.006

Huang, Q., Chen, X., Ou, C. X., Davison, R. M., \& Hua, Z. (2017). Understanding Buyers' Loyalty to a C2C Platform, the Roles of Social Capital, Satisfaction and Perceived Effectiveness of E-Commerce Institutional Mechanisms. Information Systems Journal, 27, 91-119. https://doi.org/10.1111/isj.12079

Katona, Z., Zubcsek, P. P., \& Sarvary, M. (2011). Network Effects and Personal Influences, the Diffusion of an Online Social Network. Journal of Marketing Research, 48, 425-443. https://doi.org/10.1509/jmkr.48.3.425

Lu, B., Fan, W., \& Zhou, M. (2016). Social Presence, Trust, and Social Commerce Purchase Intention, an Empirical Research. Computers in Human Behavior, 56, 225-237. https://doi.org/10.1016/j.chb.2015.11.057

McIntyre, D. P., \& Srinivasan, A. (2017). Networks, Platforms, and Strategy, Emerging Views and Next Steps. Strategic Management Journal, 38, 141-160. https://doi.org/10.1002/smj.2596

Parker, G. G., \& Van Alstyne, M. W. (2005). Two-Sided Network Effects, a Theory of Information Product Design. Management Science, 51, 1494-1504. https://doi.org/10.1287/mnsc. 1050.0400

Rokkan, A. I., \& Buvik, A. (2003). Inter-Firm Cooperation and the Problem of Free Riding Behavior, an Empirical Study of Voluntary Retail Chains. Journal of Purchasing and Supply Management, 9, 247-256. https://doi.org/10.1016/j.pursup.2003.09.004

Shankar, V., \& Bayus, B. L. (2003). Network Effects and Competition, an Empirical Analysis of the Home Video Game Industry. Strategic Management Journal, 24, 375-384. https://doi.org/10.1002/smj.296

Shin, D., \& Shin, Y. (2011). Consumers' Trust in Virtual Mall Shopping, the Role of Social Presence and Perceived Security. International Journal of Human-Computer Interaction, 27, 450-475. https://doi.org/10.1080/10447318.2011.552060

Van Baal, S., \& Dach, C. (2005). Free Riding and Customer Retention across Retailers' Channels. Journal of Interactive Marketing, 19, 75-85. https://doi.org/10.1002/dir.20036

Wathne, K. H., \& Heide, J. B. (2000). Opportunism in Interfirm Relationships, Forms, Outcomes, and Solutions. Journal of Marketing, 64, 36-51. https://doi.org/10.1509/jmkg.64.4.36.18070

Zhu, F., \& Iansiti, M. (2012). Entry into Platform-Based Markets. Strategic Management Journal, 33, 88-106. https://doi.org/10.1002/smj.941 